\title{
Limited evidence for alterations in Gag-mediated HIV replication capacity over the course of the North American epidemic (1979-present)
}

\author{
L Cotton ${ }^{1 *}$, D Chopera ${ }^{1}$, K Penney ${ }^{1}$, J Carlson², E Martin ${ }^{1}$, A Le 1 , T Kuang ${ }^{1}$, B Walker ${ }^{3}$, J Fuchs ${ }^{4}$, S Buchbinder ${ }^{4}$,

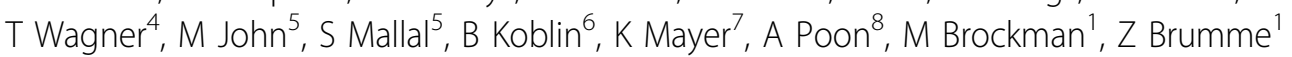

From AIDS Vaccine 2012

Boston, MA, USA. 9-12 September 2012

\section{Background}

The extent to which HIV replication capacity (RC) has changed over the epidemic's course, and the influence of HLA-associated immune pressure as its driving force remains unknown. We performed a comparative study of immune escape and RC in historic (1979-1989) and modern Gag subtype B sequences from North America.

\section{Methods}

Using phylogenetically-informed methods, we identified HLA-associated Gag polymorphisms in a historic cohort $(\mathrm{N}=239 ; 1979-1989)$. We also generated recombinant NL4-3 viruses encoding clonal plasma RNA Gag from 80 historic and 58 modern (2002-2008) sequences. Viral RC was measured using a GFP reporter T-cell assay and results were normalized to NL4-3 controls.

\section{Results}

95\% of HLA-associated polymorphisms identified in the historic cohort were consistent with published modern escape pathways. Overall, the prevalence of HLAassociated polymorphisms in the general population increased a median 1.3-fold between historic and modern sequences; however in many cases this was influenced by differences in HLA allele frequencies between HIV-infected populations examined. Of note, the prevalence of the $B * 27$ associated R264K escape mutation increased from 0.4 to $1.3 \%$ in the general population over time despite B*27 allele frequency remaining constant at $2.5 \%$. Modestly lower viral $\mathrm{RC}$ was observed for Gag recombinant viruses constructed from pre-1985 sequences (median 0.86 [IQR 0.78-0.97],
$\mathrm{N}=24$ ) compared to those from 1985-1989 (median 0.98 [IQR 0.87-1.05], N=56) and 2002-2008 (median 0.96 [IQR 0.83-0.1.10], $\mathrm{N}=58)(\mathrm{p}=0.049)$. In both historic and modern cohorts, host expression of HLA-B $* 27$ was associated with lower $\mathrm{RC}(\mathrm{p}=0.007)$. Gag codons associated with lower $\mathrm{RC}$, including S67A, were identified in an exploratory analysis.

\section{Conclusion}

Gag-mediated viral RC may have increased modestly since the beginning of the North American epidemic, despite limited evidence for HLA-driven viral sequence evolution during this time. Although mechanisms driving RC differences remain unclear, results do not support rapid and substantial accumulation of HLA-driven escape mutations in circulating North American HIV-1 sequences.

\section{Author details}

${ }^{1}$ Simon Fraser University, Burnaby, Canada. ${ }^{2}$ Microsoft Research, Los Angeles, CA, USA. ${ }^{3}$ Ragon Institute, Charlestown, MA, USA. ${ }^{4}$ San Francisco Dept of Public Health, San Francisco, CA, USA. ${ }^{5}$ Murdoch University, Perth, Australia. ${ }^{6}$ New York Blood Center, New York, NY, USA. ${ }^{7}$ Fenway Community Health, Boston, MA, USA. ${ }^{8}$ BC Centre for Excellence in HIV/AIDS, Vancouver, Canada.

Published: 13 September 2012

doi:10.1186/1742-4690-9-S2-P157

Cite this article as: Cotton et al:: Limited evidence for alterations in Gag-mediated HIV replication capacity over the course of the North American epidemic (1979-present). Retrovirology 2012 9(Suppl 2):P157.

${ }^{1}$ Simon Fraser University, Burnaby, Canada

Full list of author information is available at the end of the article

(c) 2012 Cotton et al; licensee BioMed Central Ltd. This is an Open Access article distributed under the terms of the Creative Commons Attribution License (http://creativecommons.org/licenses/by/2.0), which permits unrestricted use, distribution, and reproduction in any medium, provided the original work is properly cited. 